\title{
HIGH RATE OF CARBAPENEM-RESISTANT KLEBSIELLA PNEUMONIAE DETECTED FROM HOSPITAL EQUIPMENTS IN IRAN
}

\author{
MeHdi MOghadAMPoUR, AZHAR SALARI-JAZI and JAMSHID FAGHRI* \\ Department of Microbiology, School of Medicine, Isfahan University of Medical \\ Sciences, Isfahan, Iran
}

(Received: 31 May 2018; accepted: 28 June 2018)

\begin{abstract}
The objective of this study was to assess the prevalence, antibiogram, and related genes of carbapenem-resistant Klebsiella pneumoniae (CRKP) among hospital environment samples. A total of 250 samples were taken from different surfaces and medical devices of three hospitals in Isfahan, Iran. All samples were cultured and $K$. pneumoniae strains were identified by conventional microbiological methods and polymerase chain reaction (PCR). Antibiogram of isolates was performed by disk diffusion method and production of carbapenemases and metallo- $\beta$-lactamases (MBLs) was confirmed using modified Hodge test and E-test, respectively. Molecular detection of the related genes was carried out by PCR. Overall, 37 (14.8\%) K. pneumoniae strains were isolated, of which 34 (91.9\%) strains were resistant to carbapenems. Twenty-eight (82.4\%) isolates were positive for carbapenemases and seven $(20.6 \%)$ isolates were phenotypically MBL producers. The results of PCR showed that the prevalence of $b l a_{\mathrm{OXA}-48}, b l a_{\mathrm{NDM}}, b l a_{\mathrm{IMP}}, b l a_{\mathrm{SHV}}, b l a_{\mathrm{CTX}-\mathrm{M}}, b l a_{\mathrm{TEM}}$, and class 1 integron among CRKP isolates was $70.6 \%, 52.9 \%, 2.9 \%, 100 \%, 82.4 \%$, $55.9 \%$, and $76.5 \%$, respectively. However, bla $_{\mathrm{KPC}}, b l a_{\mathrm{GES}}, b l a_{\mathrm{IMI}}, b l a_{\mathrm{VIM}}$, and class 2 integron were not detected in any of the isolates. This study showed that the environment of our hospitals is contaminated with CRKP and it emphasizes the importance of using standard methods for infection control.
\end{abstract}

Keywords: carbapenem-resistant Klebsiella pneumoniae, CRKP, OXA-48, NDM, hospital environment

\section{Introduction}

The emergence and dissemination of carbapenem-resistant Klebsiella pneumoniae (CRKP) in hospitals is a great concern for healthcare systems worldwide [1]. CRKP is resistant to almost all antimicrobial agents, and

\footnotetext{
*Corresponding author; E-mail: faghri@med.mui.ac.ir
} 
outbreaks caused by this pathogen are associated with considerable morbidity and mortality [2]. Infected patients with CRKP can be a source of its spread in the hospital and can transfer it to other patients or even personnel [3]. Probably, the environment surrounding these patients is contaminated with these organisms and is responsible for disseminating directly or indirectly $[4,5]$. Due to the vulnerability of patients in intensive care unit (ICU), the presence of CRKP strains in the environment of this ward is very important in terms of infection control [6, 7]. Undoubtedly, knowing the status of hospital environment contamination with CRKP and the use of effective methods for disinfecting the environment and medical devices from these organisms can help control infection in ICUs. Since there has not been a study on the prevalence of these organisms in hospital environments in Iran, this study aims to evaluate the prevalence, antibiotic resistance pattern, and related genes of CRKP among hospital environment samples in the ICUs of three hospitals of Isfahan, Iran.

\section{Materials and Methods}

\section{Bacterial isolates}

During a 3-month period, from May to July 2017, bacterial strains were isolated from 250 surface samples in the ICUs of three hospitals (Alzahra, Imam Musa Kazim, and Khorshid) of Isfahan, Iran. All samples were taken using swabs from different surfaces and medical devices including hospital beds, ventilators, aerators, suctions, monitors, stethoscopes, sphygmomanometer cuffs, pulse oximeter probes, chest leads, infusion pumps, oxygen bubblers, oxygen masks, cabinets, sinks, water taps, walls, phone handsets, and washing liquid. For sampling, sterile cotton-tipped applicators were moistened in $2 \mathrm{ml}$ of sterile normal saline, rolled several times over a surface area $\left(\sim 20 \mathrm{~cm}^{2}\right)$, immersed in tryptic soy broth medium, vortexed gently, and aerobically incubated at $37{ }^{\circ} \mathrm{C}$ overnight. Then, tubes with turbidity were subcultured in blood agar and eosin methylene blue agar plates. After $24 \mathrm{~h}$ of incubation at $37^{\circ} \mathrm{C}$, all lactose-positive colonies were examined using conventional microbiological methods such as Gram-staining and biochemical (oxidase, sugar fermentation, IMViC, Kliger's iron agar, nitrate reduction, motility, etc.) tests [8]. To confirm the species, we carried out a polymerase chain reaction (PCR) detection based on the $16 \mathrm{~S}-23 \mathrm{~S}$ internal transcribed spacer sequence of $K$. pneumoniae [9]. This study was evaluated and approved by the ethics committee of Isfahan University of Medical Sciences (project no.: 395891). 
Antibiotic susceptibility testing

Antibiotic susceptibility of isolates was determined by Kirby-Bauer's disk diffusion method, according to Clinical Laboratory Standard Institute (CLSI) recommendations [10]. For this end, we used 18 antibiotic disks (MAST, UK and Liofilchem, Italy), including imipenem $(10 \mu \mathrm{g})$, meropenem $(10 \mu \mathrm{g})$, ertapenem $(10 \mu \mathrm{g})$, gentamicin $(10 \mu \mathrm{g})$, ceftaroline $(30 \mu \mathrm{g})$, piperacillin/ tazobactam $(100 / 10 \mu \mathrm{g})$, cefazolin $(30 \mu \mathrm{g})$, cefuroxime $(30 \mu \mathrm{g})$, ceftazidime $(30 \mu \mathrm{g})$, cefepime $(30 \mu \mathrm{g})$, cefoxitin $(30 \mu \mathrm{g})$, ciprofloxacin $(5 \mu \mathrm{g})$, trimethoprim/ sulfamethoxazole $(1.25 / 23.75 \mu \mathrm{g})$, tigecycline $(15 \mu \mathrm{g})$, aztreonam $(30 \mu \mathrm{g})$, amoxicillin/clavulanic acid $(20 / 10 \mu \mathrm{g})$, chloramphenicol $(30 \mu \mathrm{g})$, and tetracycline $(30 \mu \mathrm{g})$. Escherichia coli ATCC 25922 was used for quality control of disk diffusion method [10].

\section{Carbapenemase and metallo- $\beta$-lactamase (MBL) screening assays}

Carbapenemase activity was determined using the modified Hodge test (MHT) by ertapenem disk (MAST), according to CLSI guidelines [10]. To detect MBL activity, E-test method using strips containing meropenem/meropenem + EDTA (Liofilchem) was performed based on manufacturer's instructions.

PCR for the detection of antibiotic resistance genes

DNA was extracted using the boiling method and used as a template for PCR [11]. To detect antibiotic-resistant genetic elements, including $b l a_{\mathrm{KPC}}, b l a_{\mathrm{GES}}, b l a_{\mathrm{IMI}}, b l a_{\mathrm{VIM}}, b l a_{\mathrm{IMP}}, b l a_{\mathrm{NDM}}, b l a_{\mathrm{OXA}-48}, b l a_{\mathrm{SHV}}, b l a_{\mathrm{TEM}}$, and $b l a_{\mathrm{CTX}-\mathrm{M}}$ as well as class 1 and 2 integrons, separate PCR reactions were performed. The list of all target genes and corresponding primers is presented in Table I [12-19]. PCR was performed using commercially available PCR Master Mix (Ampliqon, Denmark), according to the manufacturer's instructions. Briefly, $1 \mu \mathrm{l}$ of template DNA ( $100 \mathrm{ng} / \mu \mathrm{l}), 1 \mu \mathrm{l}$ of each primer (10 pmoles $/ \mu \mathrm{l})$, and $9.5 \mu \mathrm{l}$ of DNase-free distilled water were added to $12.5 \mu \mathrm{l}$ of Master Mix in a final volume of $25 \mu \mathrm{l}$. The cycling conditions consisted of a 5-min initial denaturation step at $95{ }^{\circ} \mathrm{C}$, followed by 35 cycles of denaturation at $95{ }^{\circ} \mathrm{C}$ for $30 \mathrm{~s}$, annealing for $45 \mathrm{~s}$ at primer-specific temperatures (Table I), extension at $72{ }^{\circ} \mathrm{C}$ for $1 \mathrm{~min}$, and a final extension step at $72{ }^{\circ} \mathrm{C}$ for $10 \mathrm{~min}$. PCR products were resolved by standard electrophoresis on $1.5 \%$ agarose gel containing DNA safe stain. 
Table I. List of primers, expected amplicon size, and annealing temperatures

\begin{tabular}{|c|c|c|c|c|}
\hline $\begin{array}{l}\text { Target } \\
\text { gene }\end{array}$ & Primer sequence $\left(5^{\prime}-3^{\prime}\right)$ & $\begin{array}{c}\text { Annealing } \\
\text { temperature } \\
\left({ }^{\circ} \mathrm{C}\right)\end{array}$ & $\begin{array}{c}\text { Amplicon } \\
\text { size (bp) }\end{array}$ & References \\
\hline \multirow[t]{2}{*}{$b l a_{\mathrm{KPC}}$} & F: GATACCACGTTCCGTCTGG & 58 & 246 & [12] \\
\hline & R: GCAGGTTCCGGTTTTGTCTC & & & \\
\hline \multirow[t]{2}{*}{$b l a_{\mathrm{GES}}$} & F: GTTTTGCAATGTGCTCAACG & 53 & 371 & [13] \\
\hline & R: TGCCATAGCAATAGGCGTAG & & & \\
\hline \multirow[t]{2}{*}{$b l a_{\mathrm{IMI}}$} & F: ATGTCATTAGGTGATATGGC & 50 & 879 & [14] \\
\hline & R: GCATAATCATTTGCCGTACC & & & \\
\hline \multirow[t]{2}{*}{$b l a_{\mathrm{VIM}}$} & F: TTTGGTCGCATATCGCAACG & 66 & 500 & [15] \\
\hline & R: CCATTCAGCCAGATCGGCAT & & & \\
\hline \multirow[t]{2}{*}{$b l a_{\mathrm{IMP}}$} & F: GTTTATGTTCATACATCG & 45 & 440 & {$[15]$} \\
\hline & R: GGTTTAACAAAACAACCAC & & & \\
\hline \multirow[t]{2}{*}{$b l a_{\mathrm{NDM}}$} & F: GGGCAGTCGCTTCCAACGGT & 52 & 475 & [16] \\
\hline & R: GTAGTGCTCAGTGTCGGCAT & & & \\
\hline \multirow[t]{2}{*}{$b l a_{\text {OXA- } 48}$} & F: GCGTGGTTAAGGATGAACAC & 60 & 438 & {$[17]$} \\
\hline & R: CATCAAGTTCAACCCAACCG & & & \\
\hline \multirow[t]{2}{*}{$b l a_{\mathrm{SHV}}$} & F: ATGCGTTATATTCGCCTGTG & 60 & 753 & [15] \\
\hline & R: TGCTTTGTTATTCGGGCCAA & & & \\
\hline \multirow[t]{2}{*}{ bla $a_{\mathrm{TEM}}$} & F: AAACGCTGGTGAAAGTA & 45 & 752 & {$[15]$} \\
\hline & R: AGCGATCTGTCTAT & & & \\
\hline \multirow[t]{2}{*}{$b l a_{\mathrm{CTX}-\mathrm{M}}$} & F: TTTGCGATGTGCAGTACCAGTAA & 51 & 544 & {$[18]$} \\
\hline & R: CGATATCGTTGGTGGTGCCATA & & & \\
\hline \multirow[t]{2}{*}{ intI1 } & F: GGTCAAGGATCTGGATTTCG & 52 & 484 & [19] \\
\hline & R: ACATGCGTGTAAATCATCGTC & & & \\
\hline \multirow[t]{2}{*}{ intI2 } & F: CACGGATATGCGACAAAAAGGT & 54 & 789 & [19] \\
\hline & R: GTAGCAAACGAGTGACGAAATG & & & \\
\hline
\end{tabular}

\section{Results}

\section{Bacterial isolates}

Table II demonstrates the relative frequency of CRKP strains isolated from hospital surfaces and medical devices. Overall, 250 samples were cultured, of which $28(11.2 \%)$ samples were negative and 37 (14.8\%) samples were contaminated by $K$. pneumoniae strains.

\section{Antibiotic susceptibility testing}

Table III demonstrates the results of antibiotic susceptibility testing in hospital environment isolates. The highest resistance rate was obtained for ertapenem, cefepime, ceftazidime, ceftaroline, cefuroxime, and cefazolin with $91.9 \%$. 
Table II. Relative frequency of CRKP strains isolated from hospital surfaces and medical devices

\begin{tabular}{|c|c|c|c|c|}
\hline Sampling site & $\begin{array}{l}\text { Sample } \\
\text { size }\end{array}$ & $\begin{array}{c}\text { Positive cultures } \\
{[n(\%)]}\end{array}$ & $\begin{array}{l}\text { K. pneumoniae } \\
\text { isolates }[n(\%)]\end{array}$ & $\begin{array}{c}\text { CRKP isolates } \\
{[n(\%)]}\end{array}$ \\
\hline Hospital bed & 61 & $60(98.4)$ & $10(16.7)$ & $10(100.0)$ \\
\hline Ventilator & 47 & $42(89.4)$ & $6(14.3)$ & $5(83.3)$ \\
\hline $\begin{array}{l}\text { Sphygmomanometer } \\
\text { cuff }\end{array}$ & 25 & $25(100.0)$ & $10(40.0)$ & $9(90.0)$ \\
\hline Sink & 21 & $17(80.9)$ & $3(17.6)$ & $2(66.7)$ \\
\hline Oxygen bubbler & 20 & $13(65.0)$ & $1(7.7)$ & $1(100.0)$ \\
\hline Wall & 16 & $13(81.3)$ & $1(7.7)$ & $1(100.0)$ \\
\hline Suction & 10 & $7(70.0)$ & $2(28.6)$ & $2(100.0)$ \\
\hline Pulse oximeter probe & 9 & $9(100.0)$ & $2(22.2)$ & $2(100.0)$ \\
\hline Cabinet & 8 & $6(75.0)$ & $0(0.0)$ & $0(0.0)$ \\
\hline Water tap & 6 & $5(83.3)$ & $0(0.0)$ & $0(0.0)$ \\
\hline Monitor & 5 & $5(100.0)$ & $0(0.0)$ & $0(0.0)$ \\
\hline Aerator & 4 & $2(50.0)$ & $0(0.0)$ & $0(0.0)$ \\
\hline Infusion pump & 4 & $4(100.0)$ & $0(0.0)$ & $0(0.0)$ \\
\hline Stethoscope & 4 & $4(100.0)$ & $0(0.0)$ & $0(0.0)$ \\
\hline Chest lead & 3 & $3(100.0)$ & $1(33.3)$ & $1(100.0)$ \\
\hline Oxygen mask & 3 & $3(100.0)$ & $1(33.3)$ & $1(100.0)$ \\
\hline Phone handset & 3 & $3(100.0)$ & $0(0.0)$ & $0(0.0)$ \\
\hline Washing liquid & 1 & $0(0.0)$ & $0(0.0)$ & $0(0.0)$ \\
\hline Total & 250 & $222(88.8)$ & 37 (16.7) & 34 (91.9) \\
\hline
\end{tabular}

Note: CRKP: carbapenem-resistant Klebsiella pneumonia.

Table III. Antibiotic susceptibility of $K$. pneumoniae isolates $(n=37)$

\begin{tabular}{lccc}
\hline Antibiotic & Susceptible $[n(\%)]$ & Intermediate $[n(\%)]$ & Resistant $[n(\%)]$ \\
\hline Imipenem & $10(27.0)$ & $3(8.1)$ & $24(64.9)$ \\
Meropenem & $3(8.1)$ & $1(2.7)$ & $33(89.2)$ \\
Ertapenem & $3(8.1)$ & $0(0.0)$ & $34(91.9)$ \\
Gentamicin & $7(18.9)$ & $0(0.0)$ & $30(81.1)$ \\
Ceftaroline & $3(8.1)$ & $0(0.0)$ & $34(91.9)$ \\
Piperacillin/tazobactam & $4(10.8)$ & $0(0.0)$ & $33(89.2)$ \\
Cefazolin & $3(8.1)$ & $0(0.0)$ & $34(91.9)$ \\
Cefuroxime & $3(8.1)$ & $0(0.0)$ & $34(91.9)$ \\
Ceftazidime & $3(8.1)$ & $0(0.0)$ & $34(91.9)$ \\
Cefepime & $3(8.1)$ & $0(0.0)$ & $34(91.9)$ \\
Cefoxitin & $5(13.5)$ & $5(13.5)$ & $27(73.0)$ \\
Ciprofloxacin & $4(10.8)$ & $0(0.0)$ & $33(89.2)$ \\
Trimethoprim/sulfamethoxazole & $13(35.1)$ & $1(2.7)$ & $23(62.2)$ \\
Tigecycline & $19(51.4)$ & $7(18.9)$ & $11(29.7)$ \\
Aztreonam & $5(13.5)$ & $0(0.0)$ & $32(86.5)$ \\
Amoxicillin/clavulanic acid & $3(8.1)$ & $1(2.7)$ & $33(89.2)$ \\
Chloramphenicol & $14(37.8)$ & $8(21.6)$ & $15(40.6)$ \\
Tetracycline & $11(29.7)$ & $4(10.8)$ & $22(59.5)$ \\
\hline
\end{tabular}


Tigecycline was the most effective antibiotic with 51.4\% susceptibility rate followed by chloramphenicol (37.8\%) and tetracycline (29.7\%). Among the carbapenems, the highest and the lowest resistance rates were detected for ertapenem (91.9\%) and imipenem (64.9\%), respectively. Overall, 34 (91.9\%) isolates were resistant to carbapenems.

\section{Carbapenemase and MBL screening assays}

The results of MHT on 34 isolates with resistance to carbapenems showed that $28(82.4 \%)$ isolates were positive and $6(17.6 \%)$ isolates were negative. In addition, phenotypic MBL production testing on these isolates identified 7 $(20.6 \%)$ isolates as positive, $8(23.5 \%)$ isolates as negative, and $19(55.9 \%)$ isolates with non-determinable results.

\section{PCR for the detection of antibiotic resistance genes}

All CRKP isolates were examined by PCR for the presence of the special antibiotic resistance genetic elements. Twenty-four $(70.6 \%)$ isolates harbored $b l a_{\mathrm{OXA}-48}, 18(52.9 \%)$ isolates were positive for the $b l a_{\mathrm{NDM}}$, and $b l a_{\mathrm{IMP}}$ was detected in $1(2.9 \%)$ isolate. Moreover, nine $(26.5 \%)$ isolates had both bla $a_{\mathrm{NDM}}$ and bla $a_{\text {OXA-48, }}$, simultaneously. Extended-spectrum $\beta$-lactamases (ESBLs)-encoding genes including $b l a_{\mathrm{SHV}}, b_{\mathrm{CTX}-\mathrm{M}}$, and $b l a_{\mathrm{TEM}}$ were identified in $100 \%, 82.4 \%$, and $55.9 \%$ isolates, respectively. In addition, $16(47.1 \%)$ isolates had $b l a_{\mathrm{SHV}}$, $b l a_{\mathrm{CTX}-\mathrm{M}}$, and $b l a_{\mathrm{TEM}}$ genes, concurrently. Three $(8.8 \%)$ isolates were positive for the presence of $b l a_{\mathrm{OXA}-48}, b l a_{\mathrm{NDM}}, b l a_{\mathrm{SHV}}, b l a_{\mathrm{CTX}-\mathrm{M}}$, and $b l a_{\mathrm{TEM}}$, together. Nevertheless, the results of PCR were negative for $b l a_{\mathrm{KPC}}, b l a_{\mathrm{GES}}, b l a_{\mathrm{IMI}}$, and bla $a_{\mathrm{VIM}}$. Furthermore, 26 (76.5\%) isolates harbored class 1 integron, but class 2 integron was not detected in any of the isolates.

\section{Discussion}

In this study, we documented the existence of CRKP in the hospital environment and the surfaces of medical devices. As we know that CRKP can survive for more than 2 weeks on dry surfaces [20], this finding reveals the role of the hospital environment as a source of the transmission of CRKP to the hospitalized patients. In this study, the isolation rate of $K$. pneumoniae from hospital environment samples was $14.8 \%$. In several studies conducted in Iran 
that used the same method (wet sterile swab) for sampling, the isolation rate of $K$. pneumoniae from hospital environment samples was less than ours: Mehraban et al. (0.4\%) [21], Ayatollahi et al. (4.5\%) [22], Ekrami et al. (4.7\%) [23], and Zazouli et al. (5\%) [24]. This difference can be due to the difference in the level of environment contamination in the hospitals studied, the sampling ward, the sampling time, the sampling site, and cultivation method. Among the medical devices and surfaces, the highest level of relative contamination with $K$. pneumoniae was detected in sphygmomanometer cuffs $(40 \%)$, followed by chest leads $(33.3 \%)$, oxygen masks $(33.3 \%)$, suctions $(28.6 \%)$, pulse oximeter probes $(22.2 \%)$, sinks $(17.6 \%)$, hospital beds $(16.7 \%)$, ventilators (14.3\%), oxygen bubblers (7.7\%), and walls (7.7\%). CRKP strains were isolated from 10 of the 18 sites sampled: hospital beds, ventilators, sphygmomanometer cuffs, sinks, suctions, pulse oximeter probes, oxygen bubbler, wall, chest lead, and oxygen mask. In the study by Lerner et al. [1] in Israel, they have identified carbapenem-resistant Enterobacteriaceae strains in only 5 of the 14 sites sampled. About the antibiogram results of $K$. pneumoniae isolates, the highest resistance rate was observed for $\beta$-lactam antibiotics; however, the lowest resistance rate was identified for tigecycline. In this regard, the results of this study are consistent with the other two studies conducted on clinical isolates in the hospitals studied $[25,26]$. In this study, bla $a_{\text {OXA-48 }}$ was the most prevalent carbapenemase detected, followed by bla $a_{\mathrm{NDM}}$. Similarly, our findings are in parallel with the studies of Solgi et al. $[25,26]$ in our region. We detected $b a_{\mathrm{IMP}}$ in one CRKP isolate. This isolate was obtained from a ventilator in the ICU of Alzahra hospital and was resistant to all the aforementioned antibiotics except gentamicin and chloramphenicol. Moreover, this isolate carried bla $a_{\text {OXA-48, }}$, bla $a_{\mathrm{CTX}-\mathrm{M}}, b l a_{\mathrm{TEM}}, b l a_{\mathrm{SHV}}$, and class 1 integron, simultaneously. To the best of our knowledge, this is the second report of $b l a_{\mathrm{IMP}}$-harbored $K$. pneumoniae from Iran after Khorvash et al. [27]. This study showed a high prevalence of ESBLs-encoding genes (bla $a_{\mathrm{SHV}}$, bla $_{\mathrm{CTX}-\mathrm{M}}$, and $\left.b l a_{\mathrm{TEM}}\right)$ among CRKP isolates, which is consistent with other studies conducted in Isfahan [25, 26] and Iran [28-30]. However, we have not detected bla $a_{\mathrm{KPC}}, b_{\mathrm{GES}}$, bla $_{\mathrm{IMI}}$, and bla ${ }_{\mathrm{VIM}}$ among CRKP isolates. In this regard, studies that were previously carried out in Isfahan have not been able to identify these genes [26, 31, 32]. On the contrary, Khorvash et al. [27] in their study identified $b l a_{\mathrm{VIM}}$ in $10.3 \%$ of CRKP isolates from clinical isolates of Alzahra hospital. In conclusion, this study showed the existence of CRKP isolates in the patients' surroundings in the ICUs of our hospitals. It emphasizes the importance of using standard methods of infection control for disinfecting surfaces of medical devices and hospital environment. 


\section{Acknowledgements}

The authors would like to thank the Department of Microbiology of Isfahan University of Medical Sciences.

\section{Conflict of Interest}

The authors declare no conflict of interest.

\section{References}

1. Lerner, A., Adler, A., Abu-Hanna, J., Meitus, I., Navon-Venezia, S., Carmeli, Y.: Environmental contamination by carbapenem-resistant Enterobacteriaceae. J Clin Microbiol 51, 177-181 (2013).

2. Gregory, C. J., Llata, E., Stine, N., Gould, C., Santiago, L. M., Vazquez, G. J., Robledo, I. E., Srinivasan, A., Goering, R. V., Tomashek, K. M.: Outbreak of carbapenem-resistant Klebsiella pneumoniae in Puerto Rico associated with a novel carbapenemase variant. Infect Control Hosp Epidemiol 31, 476-484 (2010).

3. Schwaber, M. J., Lev, B., Israeli, A., Solter, E., Smollan, G., Rubinovitch, B., Shalit, I., Carmeli, Y.: Containment of a country-wide outbreak of carbapenem-resistant Klebsiella pneumoniae in Israeli hospitals via a nationally implemented intervention. Clin Infect Dis 52, 848-855 (2011).

4. de Oliveira, A. C., Damasceno, Q. S.: Surfaces of the hospital environment as possible deposits of resistant bacteria: A review. Rev Esc Enferm USP 44, 1118-1123 (2010).

5. French, G. L., Otter, J. A., Shannon, K. P., Adams, N. M., Watling, D., Parks, M. J.: Tackling contamination of the hospital environment by methicillin-resistant Staphylococcus aureus (MRSA): A comparison between conventional terminal cleaning and hydrogen peroxide vapour decontamination. J Hosp Infect 57, 31-37 (2004).

6. Chetchotisakd, P., Phelps, C. L., Hartstein, A. I.: Assessment of bacterial cross-transmission as a cause of infections in patients in intensive care units. Clin Infect Dis 18, 929-937 (1994).

7. Weist, K., Pollege, K., Schulz, I., Ruden, H., Gastmeier, P.: How many nosocomial infections are associated with cross-transmission? A prospective cohort study in a surgical intensive care unit. Infect Control Hosp Epidemiol 23, 127-132 (2002).

8. Podschun, R., Ullmann, U.: Klebsiella spp. as nosocomial pathogens: Epidemiology, taxonomy, typing methods, and pathogenicity factors. Clin Microbiol Rev 11, 589-603 (1998).

9. Liu, Y., Liu, C., Zheng, W., Zhang, X., Yu, J., Gao, Q., Hou, Y., Huang, X.: PCR detection of Klebsiella pneumoniae in infant formula based on $16 \mathrm{~S}-23 \mathrm{~S}$ internal transcribed spacer. Int J Food Microbiol 125, 230-235 (2008).

10. Clinical and Laboratory Standards Institute (CLSI): Performance Standards for Antimicrobial Susceptibility Testing; 27th ed. CLSI supplement M100. CLSI, Wayne, PA, 2017. 
11. Amiri, A., Firoozeh, F., Moniri, R., Zibaei, M.: Prevalence of CTX-M-Type and PER extended-spectrum $\beta$-lactamases among Klebsiella spp. isolated from clinical specimens in the teaching Hospital of Kashan, Iran. Iran Red Crescent Med J 18, e22260 (2016).

12. Hindiyeh, M., Smollen, G., Grossman, Z., Ram, D., Davidson, Y., Mileguir, F., Vax, M., Ben David, D., Tal, I., Rahav, G., Shamiss, A., Mendelson, E., Keller, N.: Rapid detection of bla $a_{\mathrm{KPC}}$ carbapenemase genes by real-time PCR. J Clin Microbiol 46, 2879-2883 (2008).

13. Queenan, A. M., Bush, K.: Carbapenemases: The versatile $\beta$-lactamases. Clin Microbiol Rev 20, 440-458 (2007).

14. Du, J., Li, P., Liu, H., Lu, D., Liang, H., Dou, Y.: Phenotypic and molecular characterization of multidrug resistant Klebsiella pneumoniae isolated from a university teaching hospital, China. PLoS One 9, e95181 (2014).

15. Hujer, K. M., Hujer, A. M., Hulten, E. A., Bajaksouzian, S., Adams, J. M., Donskey, C. J., Ecker, D. J., Massire, C., Eshoo, M. W., Sampath, R., Thomson, J. M., Rather, P. N., Craft, D. W., Fishbain, J. T., Ewell, A. J., Jacobs, M. R., Paterson, D. L., Bonomo, R. A.: Analysis of antibiotic resistance genes in multidrug-resistant Acinetobacter sp. isolates from military and civilian patients treated at the Walter Reed Army Medical Center. Antimicrob Agents Chemother 50, 4114-4123 (2006).

16. Voulgari, E., Gartzonika, C., Vrioni, G., Politi, L., Priavali, E., Levidiotou-Stefanou, S., Tsakris, A.: The Balkan region: NDM-1-producing Klebsiella pneumoniae ST11 clonal strain causing outbreaks in Greece. J Antimicrob Chemother 69, 2091-2097 (2014).

17. Preechachuawong, P., Santimaleeworagun, W., Jitwasinkul, T., Samret, W.: Detection of New Delhi metallo-beta-lactamase-1-producing Klebsiella pneumoniae at a general hospital in Thailand. Southeast Asian J Trop Med Public Health 46, 1031-1036 (2015).

18. Edelstein, M., Pimkin, M., Palagin, I., Edelstein, I., Stratchounski, L.: Prevalence and molecular epidemiology of CTX-M extended-spectrum $\beta$-lactamase-producing Escherichia coli and Klebsiella pneumoniae in Russian hospitals. Antimicrob Agents Chemother 47, 3724-3732 (2003).

19. Machado, E., Canton, R., Baquero, F., Galan, J. C., Rollan, A., Peixe, L., Coque, T. M.: Integron content of extended-spectrum- $\beta$-lactamase-producing Escherichia coli strains over 12 years in a single hospital in Madrid, Spain. Antimicrob Agents Chemother 49, 1823-1829 (2005).

20. Havill, N. L., Boyce, J. M., Otter, J. A.: Extended survival of carbapenem-resistant Enterobacteriaceae on dry surfaces. Infect Control Hosp Epidemiol 35, 445-447 (2014).

21. Mehraban, F., Nateghi Rostami, M., Douraghi, M., Dolati, M.: Prevalence of environmental Gram-negative bacilli in the intensive care units of hospitals from the city of Qom. Infect Epidemiol Microbiol 2, 5-7 (2016).

22. Ayatollahi, A. A., Amini, A., Darsanaki, R. K., Rahimi, S.: The prevalence of Gramnegative bacilli in the environment and the equipments: A case study in hospitals of the East of Golestan Province, Iran. J Med Bacteriol 5, 15-21 (2017).

23. Ekrami, A., Kayedani, A., Jahangir, M., Kalantar, E., Jalali, M.: Isolation of common aerobic bacterial pathogens from the environment of seven hospitals, Ahvaz, Iran. Jundishapur J Microbiol 4, 75-82 (2011).

24. Zazouli, M. A., Yazdani-Charati, J., Ahanjan, M., Langroodi, M. H., Eslamifar, M.: Bacterial contamination of environmental surfaces in two educational hospitals under the auspices of Mazandaran University of Medical Sciences. J Health Field 3, 36-41 (2017). 
25. Solgi, H., Badmasti, F., Aminzadeh, Z., Giske, C. G., Pourahmad, M., Vaziri, F., Havaei, S. A., Shahcheraghi, F.: Molecular characterization of intestinal carriage of carbapenemresistant Enterobacteriaceae among inpatients at two Iranian university hospitals: First report of co-production of $b l a_{\mathrm{NDM}-7}$ and $b l a_{\mathrm{OXA}-48}$. Eur J Clin Microbiol Infect Dis 36, 2127-2135 (2017).

26. Solgi, H., Badmasti, F., Giske, C. G., Aghamohammad, S., Shahcheraghi, F.: Molecular epidemiology of NDM-1- and OXA-48-producing Klebsiella pneumoniae in an Iranian hospital: Clonal dissemination of ST11 and ST893. J Antimicrob Chemother 73, 1517-1524 (2018).

27. Khorvash, F., Yazdani, M. R., Soudi, A. A., Shabani, S., Tavahen, N.: Prevalence of acquired carbapenemase genes in Klebsiella pneumoniae by multiplex PCR in Isfahan. Adv Biomed Res 6, 41 (2017).

28. Shahraki-Zahedani, S., Moghadampour, M., Bokaeian, M., Ansari-Moghaddam, A.: Prevalence of CTX-M-8 and CTX-M-15 type extended-spectrum beta-lactamases between Klebsiella pneumoniae spp. isolated from Zahedan, Southeast Iran. J Chemother 28, 343-345 (2016).

29. Shahraki-Zahedani, S., Rigi, S., Bokaeian, M., Ansari-Moghaddam, A., Moghadampour, M.: First report of TEM-104-, SHV-99-, SHV-108-, and SHV-110-producing Klebsiella pneumoniae from Iran. Rev Soc Bras Med Trop 49, 441-445 (2016).

30. Eskandari-Nasab, E., Moghadampour, M., Tahmasebi, A.: Prevalence of $b l a_{\text {СтХ-м gene }}$ among extended-spectrum $\beta$-lactamases producing Klebsiella pneumoniae clinical isolates in Iran: A meta-analysis. Iran J Med Sci 43, 347-354 (2018).

31. Fazeli, H., Norouzi-Barough, M., Ahadi, A. M., Shokri, D., Solgi, H.: Detection of New Delhi metallo-beta-lactamase-1 (NDM-1) in carbapenem-resistant Klebsiella pneumoniae isolated from a university hospital in Iran. Hippokratia 19, 205-209 (2015).

32. Gheitani, L., Fazeli, H., Moghim, S., Nasr Isfahani, B.: Frequency determination of carbapenem-resistant Klebsiella pneumoniae (CRKP) isolated from hospitals in Isfahan of Iran and evaluation of synergistic effect of colistin and meropenem on them. Cell Mol Biol 64, 70-74 (2018). 